\title{
Perspectives on Politics Editors' Report, 2020
}

MICHAEL BERNHARD | EDITOR-IN-CHIEF

DANIEL O'NEILL | ASSOCIATE EDITOR \& BOOK REVIEW EDITOR

JENNIFER BOYLAN | MANAGING EDITOR

Wis report covers the operation of Perspectives on Polifics from January 1 to December 31, 2020. The end date marks three years and seven months into our initial four-year agreement with the American Political Science Association to edit Perspectives on Politics. Last year, after a rigorous external review by the association, we negotiated a two-year extension and thus will continue to edit the journal through May 2023, for a total of six years. We thank the external review committee and the leadership of the association for their continued confidence in us.

Despite the unusual circumstances under which we operated this past year, we were able to fulfill our page budgets and make our publication deadlines due to the diligence of the managing editor and our editorial assistants, as well as the production team at Cambridge University Press.' We continue to accumulate a healthy supply of articles and reflection essays that are published online on our FirstView ${ }^{2}$ webpage on Cambridge Core prior to their appearance in print.

Like past reports, we will discuss this year's editorial and technical developments, and report summary statistics in a number of important areas including submissions, editorial decision-making, impact, and the book review section. However, this year we will also discuss the difficulties we confronted in publishing the journal during the public health crisis provoked by the COVID-19 pandemic.

\section{EDITING IN A TIME OF PLAGUE}

The onset of COVID- 19 meant we had to change how we work. We no longer met in-person. Our staff meetings and editorial decision meetings are now done remotely over Zoom, Skype, or phone. This transition was not difficult and did not impede our operation unduly. We anticipate moving back to face-to-face operations in the fall of 2021.

In the initial phases of the pandemic, when many colleagues faced difficult challenges in adapting to life in isolation, submissions initially slowed down drastically, but this did not last long. There were several reports in the blogosphere this spring that, even though total submissions to journals were not strongly affected by the pandemic, in some cases submissions by women were down and those by men were up. We were concerned about this, and thus we contacted Jon Gurstelle, APSA's Director of Publications, who has more fine-grained data regarding the demographics on submissions. Jon ran a comparative analysis of the periods from March 1 to May 13 in 2019 and 2020. Compared to 2019, submissions by self-identified female au- thors at POP were actually up (see table 1).

Table 1: Authorship by Gender Self-Identification

\begin{tabular}{|l|r|r|}
\hline All Authors & $\mathbf{2 0 1 9}$ & $\mathbf{2 0 2 0}$ \\
\hline Female & 44 & 60 \\
Male & 85 & 93 \\
Non-binary & 2 & 0 \\
Prefer not to say & 6 & 12 \\
\hline Corresponding Authors & 2019 & 2020 \\
\hline Female & 33 & 45 \\
Male & 76 & 75 \\
Non-binary & 2 & 0 \\
Prefer not to say & 5 & 9 \\
\hline Coauthors & 2019 & 2020 \\
\hline Female & 11 & 15 \\
Male & 9 & 18 \\
Non-binary & 0 & 0 \\
Prefer not to say & 1 & 3 \\
\hline
\end{tabular}

In terms of the external review of articles, many colleagues have faced challenges due to the pandemic such as greater responsibility for the health of loved ones, increased care and educational responsibilities for children, and the challenges of moving to an online teaching environment. Because of this, many reviewers understandably needed longer to complete external manuscript reviews. Because of the sensitivity of the added responsibilities and tensions our colleagues face, we have decreased the number of reminders we send, and have put inquiries on late reviews on a personal basis. This is somewhat more time-consuming for the editors, but we feel it is necessary. We have also not harped on late reviews. When colleagues are unable to complete them, we have found ways to make decisions with fewer reports or have found alternate reviewers. We were amazed at the generosity of our colleagues in continuing to review under the adverse conditions in which we were all operating. We express thanks to all those who continued to support the journal throughout this difficult period.

On the book review side of the journal, matters have been very challenging. Not only did we have the same sorts of delays with the completion of reviews, similar to what occurred with manuscripts, the pandemic caused the breakdown of global supply chains for almost all university presses with the result that the number of books sent to us for consideration initially dropped precipitously, and the Department of Political Science 
at the University of Florida, where we receive book submissions, remained closed for months. However, we were able to ensure our ability to receive books by making weekly mail runs to the UF loading dock and creating a roving bookmobile for hand-delivering books to our editorial assistants, so they could continue their work of locating suitable reviewers and mailing books to them. In addition, we worked closely with Jon Gurstelle at APSA to publicize this problem to the association's membership, and to encourage authors to work with their presses to ensure that their books were sent to us. We also worked closely with both Oxford University Press and Cambridge University Press to arrange bulk deliveries of books published during the pandemic towards the end of the summer. On that score, we owe a big thanks to Mark Zadrozny at Cambridge for helping make this happen. Finally, we have been in close contact with a number of other major university presses, encouraging them to send hard copies of their books for review as soon as it became feasible. The good news is that, as a result of all these measures, there was no drop-off in the number of books reviewed during 2020 (see table 9 below).

\section{EDITORIAL DEVELOPMENTS}

\section{Expansion of Content}

In 2020 the editors and APSA negotiated an expansion of the page budget per issue from 296 pages to 325 . For 2021 this was further expanded to 348 pages. This additional space has been devoted to articles and reflections. When we first started editing the journal we allocated 148 pages to both the articles and reflections, and 148 to book reviews. As of 2021 we have expanded the front section of the journal to 200 pages, an increase of over $25 \%$.

\section{Thematic Grouping of Articles}

Following the success of our calls for papers on "Trump: Causes and Consequences" ${ }^{3}$ and "Celebrity and Politics," 4 we issued two calls for papers this year in response to the momentous events of our times. The first of these was on "Pandemic Politics." ${ }^{5}$ The call closed on October 1, 2020. The response was excellent-we received over 138 submissions and have so far accepted six articles. Several others received "revise and resubmit" decisions and are still under review. The first of the accepted articles has already appeared on FirstView. ${ }^{6}$ If all goes well, we will publish this material in Volume 20, Issue 1 (2022). We will feature a selection of these papers in our sponsored panels at the APSA Annual Meeting this fall.

The second call for papers concerned the "Blacks Lives Matter" movement and asked potential authors to explore the state of BLM, its impact, and potential ramifications. We developed this call on the initiative of one of the members of our editorial board, Christopher Sebastian Parker of the University of Washington, who will serve as guest editor on this issue. ${ }^{7}$ To date we have received only a few submissions, but consistent with past experience we expect to receive a large number of manuscripts closer to the deadline of May 31, 2021.

To date, every issue we have assembled has grouped individual papers together in special thematic sections. We feel that the grouping of kindred material helps to give readers a sense of the state of research on important issues of concern to the discipline and also helps to bring together work that is geographically and methodologically diverse, thus promoting disciplinary and regional pluralism. The special sections for Volume 18 (2020) are summarized in table 2 with links to their tables of contents.

In 2021 we have two additional special sections planned. For 19(2) we have prepared a special section on "The Politics of Immigration." And in 19(3) we plan to group together several articles that make use of "Comparative Historical Analysis."

Table 2: Special Sections in Volume 18 (2020)

\begin{tabular}{|l|l|l|}
\hline Number & Special Section & Link to ToC \\
\hline $18(1)$ & Celebrity and Politics & $\underline{\text { https://tinyurl.com/un79hxr8 }}$ \\
\hline $18(2)$ & Whither America? & $\underline{\text { https://tinyurl.com/3zxaah3j }}$ \\
\hline $18(3)$ & The Uses of Violence & $\underline{\text { https://tinyurl.com/mucx8md3 }}$ \\
\hline $18(4)$ & $\begin{array}{l}\text { Moving Beyond the } \\
\text { Glass Ceiling? }\end{array}$ & $\underline{\text { https://tinyurl.com/ybbsnb7d }}$ \\
\hline
\end{tabular}

\section{From the Editors}

Until this year, we followed a standard procedure of authoring the introductory essays to each issue ourselves. We changed that this year. For the "Celebrity and Politics" issue (18[1]), the guest editor, Samantha Majic of John Jay College, wrote an expansive introduction to the selection of articles that she curated for us. And for issue 18(4) we invited Joan Tronto, a member of the editorial board, to comment on the content of the "Moving Beyond the Glass Ceiling?" special section because of her expertise in this area. We hope to continue this practice periodically in the future.

\section{Publicity Strategies}

Embargo Dates: We continue to use embargo dates for every publication on FirstView, which is how every article is now published. Authors of manuscripts and reflections are notified of their upcoming publication date about 10- 14 days prior. Coordinated release strategies with our authors and with Cambridge Core helps our material reach the broadest possible audiences on social media.

Twitter: Our Twitter followership (@PoPpublicsphere) has grown dramatically. We began with just over 1,000 followers in 2017, which grew to 2,028 followers in Jan 2019, and now stands at a whopping 5,220 as of March 2021. Our Twitter strategy is to tweet about all FirstView publications, with abstracts and tables/figures where applicable, to include authors' Twitter handles in those tweets when possible, and to retweet relevant tweets about any of our published material (accessed through the Altmetric scores available on Cambridge Core).

Facebook: Our Facebook page now has 651 total likes and 704 total followers. The post about an article with the highest estimated reach in 2020 (11/10/2020), came when 2,113 Facebook users viewed our post about David Art's Reflection,

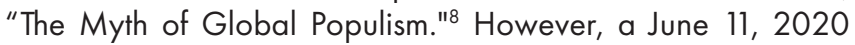
post alerting political scientists of the need to ensure that their publishers were sending a review copy of their recent book publications to our offices reached an estimated 8,177 users.

\section{TECHNICAL INNOVATIONS}

\section{Dataverse}

A total of 93 datasets have published on our Dataverse page, 
as of January 2021.9 This includes 635 individual files (read. me files, replication files, datasets, etc.). Per a suggestion by board member Reșat Bayer at our 2019 APSA meeting, authors of work published in Perspectives prior to Volume 17, which also presented statistical evidence, were contacted in order to offer them the opportunity to upload replication files to our page. Thus far, one scholar added their replication files to our Dataverse page and, in three other cases, links to replication files already hosted elsewhere were added to publication pages on Cambridge Core.

\section{SUBMISSIONS AND PROCESSING}

\section{Number of Submissions}

The number of submissions expanded substantially this year (see table 3). We received 571 new and 164 revised manuscripts. Both the individual and total numbers represent new highs for the journal. Our early fears that the pandemic would slow down academic productivity proved to be exaggerated. A part of this increase was the call for "Pandemic Politics," which brought in a substantial number of submissions which we might well not have seen in its absence. Still, without the call, the total would have exceeded last year by almost 70 submissions.

We were asked by the leadership of APSA to push for the internationalization of the journal and its content. This year for the first time the number of submissions from outside the United States almost equaled that from within (see table 4).

\section{Table 3: Manuscript Submissions per Year}

\begin{tabular}{|l|l|l|}
\hline $\begin{array}{l}\text { Time } \\
\text { Period }\end{array}$ & $\begin{array}{l}\text { New Manuscripts } \\
\text { Received }\end{array}$ & $\begin{array}{l}\text { Revised Manuscripts } \\
\text { Received }\end{array}$ \\
\hline 2020 & 571 & 164 \\
\hline 2019 & 356 & 94 \\
\hline 2018 & 316 & 101 \\
\hline 2017 & 294 & 83 \\
\hline 2016 & 321 & 51 \\
\hline 2015 & 258 & 53 \\
\hline 2014 & 253 & 47 \\
\hline
\end{tabular}

Table 4: Number of Manuscripts Received Based on the Location of the Corresponding Author

(based on available data)

\begin{tabular}{|l|l|l|}
\hline Year & US & Outside of US \\
\hline 2020 & $286(51.2 \%)$ & $273(48.8 \%)$ \\
\hline 2019 & $190(53.8 \%)$ & $163(46.2 \%)$ \\
\hline 2018 & $181(57.3 \%)$ & $135(42.7 \%)$ \\
\hline 2017 & $164(56.6 \%)$ & $126(43.4 \%)$ \\
\hline 2016 & $190(59.9 \%)$ & $127(40.1 \%)$ \\
\hline 2015 & $155(60.8 \%)$ & $100(39.2 \%)$ \\
\hline 2014 & $170(67.5 \%)$ & $82(32.5 \%)$ \\
\hline
\end{tabular}

We continue to publish a substantial number of authors based outside the United States. In Volume 18 (2020), 27.1\% of the authors were employed by universities outside the United States. This was the highest percentage achieved to date, a slight increase from the previous high-Volume 16 (2018)-when the figure was $26.8 \% .^{10}$ We suspect that the difference in the rates of submission and acceptance is a function of the lesser degree of familiarity of some international colleagues with the conventions of publication in English language journals. Unfortunately, due to the pandemic we were unable to participate in panels devoted to publishing at international conferences. Scheduled talks at the Wissentschaftszentrum Berlin für Sozialforschung (WZB Berlin Social Science Center) and the World Meeting of the International Council for Central and East European Studies in Montreal were cancelled.

\section{Processing of Submissions}

Despite the pandemic we continue to reduce the time it takes for authors to get the initial decision from us (see table 5). The average time is just over a month, but the time is longer for manuscripts sent for external review. This year we declined to review a larger number of manuscripts because of the call for papers (see below), and we believe this explains a good part of the substantial reduction in time to first decision.

\section{Editorial Decisions}

In table 6 we present data on our editorial decisions for the first round of review in 2020. The number of manuscripts that we declined without external review (DNER) increased five percent this year, $60.9 \%$ from $55.8 \%$ in 2019 . This was a product of the call for papers on "Pandemic Politics." Because of the large number of submissions in response to the call, and limited space for publication (one issue), we were very selective in what we sent out for review. Of the 138 submissions that responded to the call we only sent 38 for external review. When these are subtracted from the table below the DNER rate is $56.8 \%$, little different from the previous year (55.8). Of the 210 submissions that went out for external review (up from 151 last year), only $39 \%(13.6 \%$ of the total submissions) were asked to revise their work for possible publication. The vast majority of these decisions were major revisions. There were three manuscripts that were conditionally accepted on the first round. As in the past these were either originally article submissions which were rejected but were then modified with the guidance of the editors into reflection essays or the publication of the APSA presidential address. No article submission to the journal was accepted on the first-round last year, and for a substantial number of papers, two rounds of revision were required.

A revision decision from the editors does not automatically translate into publication. Six out of the 70 resubmissions by authors were rejected on the second round $(8.6 \%)$. We accepted 67 articles and reflections last year, up from 33 in 2019, and 40 in 2018. We also have more space for publications now.

Table 5: Average Number of Days in Review Process

\begin{tabular}{|l|l|l|l|l|l|l|l|}
\hline Stage of Review Process & $\mathbf{2 0 2 0}$ & $\mathbf{2 0 1 9}$ & $\mathbf{2 0 1 8}$ & $\mathbf{2 0 1 7}$ & $\mathbf{2 0 1 6}$ & $\mathbf{2 0 1 5}$ & $\mathbf{2 0 1 4}$ \\
\hline Submission to Editor Assignment & 0.5 & 0.5 & 0.7 & 4.8 & 6.9 & 6.3 & 6 \\
\hline Submission to First Decision & 32.7 & 39.0 & 38.3 & 46.0 & 42.1 & 45.9 & 51.8 \\
\hline
\end{tabular}


Table 6: First Round Editorial Decisions 2020

\begin{tabular}{|l|c|c|c|}
\hline Editor Decision & Total Decisions & Frequency of Decision & Avg. Days to Decision \\
\hline Decline (No External Review) & 327 & $60.9 \%$ & 12.5 \\
\hline Decline (After External Review) & 137 & $25.5 \%$ & 66 \\
\hline Major Revision & 59 & $11.0 \%$ & 86.3 \\
\hline Minor Revision & 11 & $2.0 \%$ & 72.3 \\
\hline Conditional Accept & 3 & $0.6 \%$ & 15.7 \\
\hline Total Editor Decisions & 537 & $100 \%$ & 35.5 \\
\hline
\end{tabular}

Table 7: Outcome of First Round of the Review Process, 2014-20 (percentage)

\begin{tabular}{|l|l|l|l|l|l|l|l|}
\hline Outcome & $\mathbf{2 0 2 0}$ & $\mathbf{2 0 1 9}$ & $\mathbf{2 0 1 8}$ & $\mathbf{2 0 1 7}$ & $\mathbf{2 0 1 6}$ & $\mathbf{2 0 1 5}$ & $\mathbf{2 0 1 4}$ \\
\hline Decline (No External Review) & 60.9 & 55.8 & 59.2 & 59.4 & 69.1 & 69.6 & 64.9 \\
\hline Decline (After External Review) & 25.5 & 26.3 & 26.1 & 25.5 & 22.3 & 19.2 & 22.9 \\
\hline Major Revision & 11.0 & 14.3 & 12.4 & 10.4 & 5.5 & 7.2 & 7.4 \\
\hline Minor Revision & 2.0 & 2.9 & 1.6 & 2.7 & 2.8 & 4.0 & 3.9 \\
\hline Conditional Accept & 0.6 & 0.6 & 0.7 & 0.3 & 0.3 & 0.0 & 0.4 \\
\hline Accept & 0.0 & 0.0 & 0.0 & 1.7 & 0.0 & 0.0 & 0.4 \\
\hline
\end{tabular}

Table 7 compares this year to the previous six. As noted above we consider the uptick in "No External Review" decisions to be an artifact of the space concerns of doing a special issue out of a call for papers. Even with this anomaly, the rate is still below that of the previous editorial team.

Nothing we do would be possible without the support of external reviewers. And this year we know that our colleagues faced a number of challenges that made providing this service more difficult than normal. We salute our reviewers for extraordinary effort in difficult circumstances. While the number of reviewers who declined to review increased in 2020, from 438 to 568 , we still received 941 completed reviews for front-end manuscripts. Furthermore, of the reviews we received, about $60 \%$ of them were completed on-time. We are grateful to those who wrote reviews for sharing their time and expertise. We also thank those who, despite the personal or professional obligations that kept them from writing a review, recommended others who could replace them. These thoughtful suggestions also helped to facilitate our work.

\section{Journal Impact}

Table 8 reports the journal's impact and relative standing in the discipline for the last seven years.

The Thomson-Reuters Journal Citation Reports produce both two-year and five-year impact factors. The two-year impact factor (JIF2) continues to show recovery from its substantial decline in 2017. Our
Table 8: Journal Impact Factor, 2013-19

\begin{tabular}{|l|c|c|c|c|}
\hline Year & $\begin{array}{c}\text { 2-Year Impact } \\
\text { Factor }\end{array}$ & $\begin{array}{c}\text { Political Science } \\
\text { Rank (annual) }\end{array}$ & $\begin{array}{c}\text { 5-year Impact } \\
\text { Factor }\end{array}$ & $\begin{array}{c}\text { Political Science } \\
\text { Rank (5-year) }\end{array}$ \\
\hline 2019 & 2.398 & $41 / 181$ & 3.407 & $30 / 166$ \\
\hline 2018 & 2.326 & $39 / 176$ & 3.617 & $23 / 166$ \\
\hline 2017 & 1.714 & $53 / 169$ & 3.607 & $19 / 166$ \\
\hline 2016 & 3.234 & $8 / 165$ & 3.680 & $7 / 161$ \\
\hline 2015 & 2.462 & $10 / 163$ & 3.257 & $6 / 156$ \\
\hline 2014 & 2.132 & $11 / 161$ & 2.661 & $16 / 153$ \\
\hline 2013 & 3.035 & $2 / 157$ & 2.628 & $9 / 142$ \\
\hline
\end{tabular}

Table 9: Book Reviews Published in Volume 18 (2020)

\begin{tabular}{|l|c|c|c|c|c|}
\hline Field & $\begin{array}{c}\text { Conventional } \\
\text { Reviews }\end{array}$ & $\begin{array}{c}\text { Review } \\
\text { Essays }\end{array}$ & Critical Dialogues & Symposia & Total \\
\hline IR & 67 & 1 & 5 & 0 & 73 \\
\hline American & 69 & 0 & 6 & 2 & 77 \\
\hline Theory & 72 & 3 & 7 & 0 & 82 \\
\hline Comparative & 104 & 0 & 4 & 0 & 109 \\
\hline Total & 312 & 4 & 22 & 2 & 340 \\
\hline
\end{tabular}


stances described above. As usual, the editorial assistants were indispensable to the success of this half of the journal and went to truly extraordinary lengths to make sure there was no drop-off in the number of reviews this year. We are also deeply grateful to all of the scholars who took time to review their colleagues' work in the midst of a global pandemic. The journal and the discipline are indebted to you all.

As usual, the Book Review section strives to feature a wide range of special review formats, and this year was no exception. For example, we organized a symposium on Avidit Acharya, Matthew Blackwell, and Maya Sen's book, Deep Roots: How Slavery Still Shapes Southern Politics, as well as one on Russell Muirhead and Nancy L. Rosenblum's A Lot of People are Saying: The New Conspiracism and the Assault on Democracy. Review Essays featured Gary Goertz's assessment of a number of recent books aimed at measuring peace; Alyssa Battistoni's reading of books on "Anthropocene Politics"; Kyong-Min Son's review of recent treatments of populism, entitled "Populism's Challenge and the Uncertain Future of Liberal Democracy"; and Christopher Lebron's extended review of Nicholas Buccola's The Fire is Upon Us: James Baldwin, William F. Buckley, Jr., and the Debate Over Race in America. Finally, we had another great year of exchanges in our "Critical Dialogues" section, including those between Sheri Berman, Daron Acemoglu, and James Robinson on the history of democracy; Wendy Brown and Thomas Biebricher on neoliberalism; Carles Boix, Torben Iversen, and David Soskice on the relationship between democracy and capitalism; Karen Orren, Stephen Skowronek, Andrew Karch, and Shanna Rose on the American state; John Mearsheimer and Will Walldorf on American foreign policy; Alasia Nuti and Inés Valdez on transnational and intergenerational justice; and Murad Idris and Jennifer Pitts on comparative political theory, international law, and empire.

\section{CONCLUSION}

2020 marks the last full year in our original four-year term as editors. In summer of 2021, we will commence our two-year extension. Despite the difficulties posed by the pandemic, we managed to keep the journal on-track and continued to make progress towards the goal of soliciting a larger number of international submissions. In other areas, like reducing the number of decline decisions without external review, and increasing the impact of the journal, we managed to tread water. We look forward to the next year where we will launch what we expect to be influential issues on "Pandemic Politics" and "Black Lives Matter." We again managed to review over 350 books in a year when global supply chains in publishing collapsed for several months. We also continue to appreciate the support of Cambridge University Press, who despite their own difficulties met every commitment they made to us in producing the journal. $^{12}$ We also express our appreciation of our colleagues at APSA headquarters who supported us in a consistent and flexible way throughout this year's crisis. ${ }^{13}$ Finally, we express our appreciation to the members of our Editorial Board for stepping up and making decisions when we faced conflicts of interest, for providing advice both solicited and unsolicited, and serving as a sounding board for our ideas about the journal's operation and future. ${ }^{14}$
NOTES

1. Our work would not be possible without the committed and careful work of our editorial assistants. In 2020 they were Alec Dinnin, Karla Mundim, Marah Schlingensiepen, Dragana Svraka, Stephanie Denardo, and Graham Gallagher.

2. https://www.cambridge.org/core/journals/perspectives-on-politics/ firstview

3. https://www.cambridge.org/core/journals/perspectives-on-politics/ issue/7962BOF299AAFB71ACFA1F154BF6335A and https://www. cambridge.org/core/journals/perspectives-on-politics/issue/E6DD809BEE0B3D5F05627E5A41369362

4. https://www.cambridge.org/core/journals/perspectives-on-politics/ issue/66E6E91481 C8B7C64EC9B 19D3A38BD6D

5. https://www.cambridge.org/core/journals/perspectives-on-politics/ call-for-papers-pandemic-politics

6. https://www.cambridge.org/core/journals/perspectives-on-politics/ article/abs/exploiting-a-crisis-abortion-activism-and-the-covid 19-pandemic/1FC6BF42FC6C5594722A872D4D0940E 1

7. https://www.cambridge.org/core/journals/perspectives-on-politics/callfor-papers-black-lives-matter-special-issue

8. Reflection available here: https://www.cambridge.org/core/journals/perspectives-on-politics/article/abs/myth-of-global-populism/4768B361D346DADE91D3C150011 CB999

9. https://dataverse.harvard.edu/dataverse/perspectives

10. The balance between male and female authorship in volume 18 was 57.5 to $42.25 \%$ (based on lead author). This was an improvement over volume $17(60 / 40)$. The numbers are closer to parity when based on all authors: $54.1 \%$ to $45.9 \%$.

11. Clarivate Analytics. InCites Journal Citation Reports. Accessed February 12 2021. Available at: https://icr.incites.thomsonreuters.com/JCRJournalHomeAction.action (login required).

12. We would like to express our gratitude to Mark Zadrozny, David Mainwaring, Katrina Swartz, Wendy Moore, Jim Ansell, Alyssa Neumann, Molly Sheffer, Andrew Hyde, Linda Lindenfelser, Gavin Swanson, and Gail Naron Chalew.

13. We would also like personally to thank Paula McClain, Steven R. Smith, Jon Gurstelle, Henry Chen, and Karima Scott for the unflagging support and counsel provided by APSA. Jon and Henry oversaw a redesign of the covers of all APSA publications this year, and we thank them for working with us on this to produce a fresh new look. Henry's design skills have made for a bold new cover.

14. https://www.cambridge.org/core/journals/perspectives-on-politics/ information/editorial-board 